First publ. in: Journal of Occupational Health Psychology 12 (2007), 3, pp. 204-221

\title{
The Recovery Experience Questionnaire: Development and Validation of a Measure for Assessing Recuperation and Unwinding From Work
}

\author{
Sabine Sonnentag \\ University of Konstanz
}

\author{
Charlotte Fritz \\ Bowling Green State University
}

\begin{abstract}
Drawing on the mood regulation and job-stress recovery literature, four self-report measures for assessing how individuals unwind and recuperate from work during leisure time were developed (Study 1). Confirmatory factor analyses with a calibration and a cross-validation sample (total $N=930$ ) showed that four recovery experiences can be differentiated: psychological detachment from work, relaxation, mastery, and control (Study 2). Examination of the nomological net in a subsample of Study $2(N=271)$ revealed moderate relations of the recovery experiences with measures of job stressors and psychological well-being; relations with coping and personality variables were generally low (Study 3). Potential applications for the future use of these short 4-item measures in longitudinal and diary research are discussed.
\end{abstract}

Keywords: job stress, recovery, unwinding, scale development

Individuals who face stressful work situations experience poor psychological well-being and tend to suffer from health problems (De Lange, Taris, Kompier, Houtman, \& Bongers, 2003; Sonnentag \& Frese, 2003). For example, individuals exposed to job stressors have an increased likelihood for developing burnout and other symptoms of poor wellbeing (Demerouti, Bakker, \& Bulters, 2004; Garst, Frese, \& Molenaar, 2000). In addition, stressful work situations might negatively affect job performance (Jex, 1998).

Processes related to recovering and unwinding from job stressors can be relevant for individuals' health, well-being, and job performance (deCroon, Sluiter, \& Blonk, 2004; Eden, 2001). However, past research on recovery and recuperation from job stress mainly focused on general effects of off-job episodes such as vacations (Fritz \& Sonnentag, 2006;

Sabine Sonnentag, Department of Psychology, University of Konstanz; Charlotte Fritz, Department of Psychology, Bowling Green State University.

We are grateful to Kerstin Breustedt, Gabriele Bruns, Maike Debus, Julia Göbber, Astrid Kassner, Undine Kruel, Eva J. Mojza, Kim Prüß, Holger Roth, Jeannine Sennewald, and Gudrun Smith for their involvement in data collection and to Carmen Binnewies, Jana Kühnel, Jennifer McInroe, Eva J. Mojza, as well as to Lois Tetrick and three anonymous reviewers for helpful comments on earlier versions of this article.

Correspondence concerning this article should be addressed to Sabine Sonnentag, Department of Psychology, University of Konstanz, Postbox D 42, D- 78457 Konstanz, Germany. E-mail: sabine.sonnentag@uni-konstanz.de
Westman \& Eden, 1997) or examined specific off-job activities such as social, physical, or low-effort activities (Sonnentag, 2001; Strauss-Blasche, Reithofer, Schobersberger, Ekmekcioglu, \& Marktl, 2005). Because the underlying psychological experiences associated with recovery gained little research attention so far (for an exception see Fritz \& Sonnentag, 2005), it remains unexplored why specific off-job activities are associated with recovery.

Probably, it is not a specific activity per se that helps to recover from job stress but its underlying attributes such as relaxation or psychological distance from job-related issues. Persons may differ with respect to the specific activities they experience as recovering while the underlying psychological experiences crucial for recovery may be relatively uniform across persons. For example, one person might recover from job stress by going for a walk while the other recovers by reading a book. Although the activities are different, the underlying processes (e.g., relaxation) are rather similar. Going beyond the specific activities and examining the underlying experiences is crucial for getting more insight into the psychological processes leading to recovery. To this end, it is necessary to have reliable and valid measures available that capture the core functional aspects of such recovery experiences. In this paper, we present a new instrument that assesses specific recovery experiences, namely psychological detachment from work, relaxation, mastery, and control. In addition, we examine the relation between these recovery experiences and potential predictors (work situation 
variables, coping, and personality) as well as potential consequences (psychological well-being).

\section{Conceptualizations of Recovery}

Recovery refers to a process during which individual functional systems that have been called upon during a stressful experience return to their prestressor levels (Meijman \& Mulder, 1998). The recovery process can be seen as a process opposite to the strain process. It results in restoration of impaired mood and action prerequisites and is often also reflected in a decrease in physiological strain indicators.

To develop an understanding of successful recovery experiences we draw on theories on recovery processes (Effort-Recovery Model; Conservation of Resources Theory) as well as on the mood regulation literature. The Effort-Recovery Model (Meijman \& Mulder, 1998) holds that effort expenditure at work leads to load reactions such as fatigue or physiological activation. Under normal conditions, once the individual is no longer exposed to the work or similar demands, load reactions are reversed and recovery occurs. According to this model, it is an important precondition for recovery that the functional systems taxed during work will not be called upon any longer.

The Conservation of Resources Theory (Hobfoll, 1998) assumes that people strive to obtain, retain, and protect their resources. Resources can be external entities such as objects or financial assets as well as internal attributes such as personal characteristics or energies. Stress threatens these resources and as a consequence may harm health and well-being. To recover from stress, individuals have to gain new resources and restore threatened or lost resources. Stress recovery on a day-to-day basis particularly refers to internal resources such as energy or positive mood. Thus, the Effort-Recovery Model and the Conservation of Resources Theory suggest two complementary processes by which recovery occurs. First, it is important to refrain from work demands and to avoid activities that call upon the same functional systems or internal resources as those required at work. Second, gaining new internal resources such as energy, self-efficacy or positive mood will additionally help to restore threatened resources.

Research on mood regulation offers a more specific insight into the processes that are relevant for recovery. Because stressful work conditions often lead to impaired mood (Fuller et al., 2003), mood repair is one of the core functions of recovery. Research on mood regulation identified a range of different strategies individuals pursue to improve their mood including both cognitive and behavioral approaches (Parkinson, Totterdell, Briner, \& Reynolds, 1996; Thayer, Newman, \& McClain, 1994).

Parkinson and Totterdell (1999) suggested a classification of mood regulation strategies comprising diversionary strategies and engagement strategies. Diversionary strategies aim at avoiding a negative or stressful situation and at seeking distraction from it. Engagement strategies are characterized by confronting or accepting the negative or stressful situation. Diversionary strategies seem to be most relevant and promising for stress recovery because engagement strategies keep the individual cognitively occupied with the stressful situation and its potential effects which make recovery less likely.

\section{Recovery Experiences}

Among others, diversionary strategies comprise psychological detachment from work (i.e., mentally switching off), relaxation-oriented strategies, and mastery-oriented strategies (Parkinson \& Totterdell, 1999). These divisionary strategies, particularly detachment from work and relaxation-oriented strategies, should be useful for recovery because they imply that no further demands are made on functional systems called upon during work. Mastery-oriented strategies should support the recovery process by building up new internal resources (e.g., selfefficacy). In addition, because control is a crucial external resource that provides the opportunity to gain internal resources (Hobfoll, 1998), we propose that the experience of control is one important recovery experience.

\section{Psychological Detachment}

Although being physically away from the workplace might be important for recovery, it may not be sufficient (Hartig, Johansson, \& Kylin, 2007). We propose that becoming psychologically detached from work is a crucial aspect of any recovery process. Etzion, Eden, and Lapidot (1998) introduced the term detachment to describe an "individual's sense of being away from the work situation" (p. 579). Detachment implies not to be occupied by work-related duties such as receiving job-related phone calls at home or actively engaging in job-related activities. In our view, psychological detachment also means to disengage oneself mentally from work. It implies to stop thinking about one's work and job-related problems or opportunities. Psychological detachment from work goes beyond the pure physical absence 
from the workplace during off-job time and abstaining from job-related tasks. It implies leaving the workplace behind oneself in psychological terms (Sonnentag \& Bayer, 2005).

According to the Effort-Recovery Model, recovery occurs when no further demands are made on the functional systems called upon during work (Meijman \& Mulder, 1998). When individuals psychologically detach from work during off-job time, the chances increase that demands on the functional systems taxed during work are reduced. However, when individuals do not detach and are still thinking about job-related issues, the identical functional systems are continuously challenged and no full recovery can occur.

Empirical evidence suggests that psychological detachment is related to recovery from job stress. For example, Etzion et al. (1998) showed that detachment exerts a moderating effect on the relation between stressors and burnout. Using daily survey data, Sonnentag and Bayer (2005) reported that individuals experiencing psychological detachment from work during leisure time reported better mood at the end of the evening.

\section{Relaxation}

Relaxation is a process often associated with leisure activities. It is characterized by a state of low activation and increased positive affect (Stone, Kennedy-Moore, \& Neale, 1995). Relaxation may result from deliberately chosen activities aiming at the relaxation of body and mind such as progressive muscle relaxation (Jacobson, 1938) or meditation (Grossman, Niemann, Schmidt, \& Walach, 2004). Some degree of relaxation may also be achieved when performing other activities such as taking a light walk in a beautiful natural environment (Hartig, Evans, Jamner, Davis, \& Gärling, 2003) or listening to music (Pelletier, 2004). Many individuals expect relaxation from activities that put few social demands on them, that require little physical or intellectual effort, and that present no challenge to them (Tinsley \& Eldredge, 1995). The potential for relaxation experiences to reduce activation and to increase positive affect are important for recovery in two respects. First, as Brosschot, Pieper, and Thayer (2005) suggested, prolonged activation resulting particularly from stressful work is an important mediating mechanism by which job stressors translate into illness. Therefore, processes that reduce this prolonged activation are crucial in order to restore an organism's prestressor state. Second, Frederickson (2000) argued that positive emotions can undo the effects of negative emotions. Positive affect resulting from relaxation experiences will be helpful in reducing negative affect resulting from job stress. Empirical evidence suggests that relaxation experiences help in reducing stress-related complaints, in the short as well as in the long run (Stone et al., 1995; Van der Klink, Blonk, Schene, \& Van Dijk, 2001).

\section{Mastery Experiences}

Mastery experiences refer to off-job activities that distract from the job by providing challenging experiences and learning opportunities in other domains. These activities offer opportunities for experiencing competence and proficiency. Typical examples include taking a language class, climbing a mountain, or learning a new hobby (Fritz \& Sonnentag, 2006). Also volunteer work in which one can demonstrate one's competencies can include aspects of mastery experiences (Ruderman, Ohlott, Panzer, \& King, 2002).

Mastery experiences challenge the individual without overtaxing his or her capabilities. Attaining mastery experiences is not necessarily effortless but requires a certain degree of self-regulation. For example, for experiencing mastery by taking a language class, it is necessary to exercise some control over oneself in order to drive to the course and to overcome the impulse to spend a lazy evening at home (cf. Vohs \& Baumeister, 2004). Although mastery experiences might put additional demands on the individual, these experiences are expected to result in recovery because they will help to build up new internal resources such as skills, competencies, and self-efficacy (Bandura, 1997; Hobfoll, 1998). In addition, mastery experiences during off-job time will help in improving positive mood (Parkinson \& Totterdell, 1999).

First empirical evidence suggests that mastery experiences during off-job time are related to recovery. For example, mastery experienced during a vacation was negatively related to exhaustion after the vacation (Fritz \& Sonnentag, 2006). Similarly, the pursuit of sport-an activity that is often associated with mastery experiences-is related to an improvement in affect (Rook \& Zijlstra, 2006; Sonnentag \& Natter, 2004).

\section{Control During Leisure Time}

Individuals have a general desire to control events in their life (Kelley, 1971). Control can be described 
as a person's ability to choose an action from two or more options. Here, we will focus on the degree to which a person can decide which activity to pursue during leisure time, as well as when and how to pursue this activity.

Personal control seems to be associated with positive reactions (Burger, 1989). It can lead to a positive reevaluation of potentially stressful situations and is associated with lower distress and higher psychological well-being (Lazarus, 1966). Using an experience-sampling approach, Larson (1989) found that the experience of control during the day was positively related to happiness. Thus, individual wellbeing is increased when one feels in control of important life domains (Bandura, 1997).

In contrast, the perception that one's ability to react to and influence the social world is reduced can be associated with higher levels of psychological distress (Rosenfield, 1989). This experience of low control can further result in negative self-evaluations and decreased self-worth which again can be associated with anxiety or depression (Rosenfield, 1989).

The experience of control during leisure time may satisfy one's desire for control by increasing selfefficacy and feelings of competence, which in turn promote well-being. In this sense, control may act as an external resource that enhances recovery from work during off-job time. In addition, control during leisure time gives the individual the opportunity to choose those specific leisure activities that he or she prefers and that may be especially supportive for the recovery process. Increased levels of recovery may then become evident in a person's increased wellbeing and potential for action regulation.

Accordingly, Griffin, Fuhrer, Stansfeld, and Marmot (2002) found that women experiencing low control at home showed higher levels of depression five years later than women high in control at home while men experiencing low control at home showed higher levels of depression as well as anxiety than men with high control at home.

\section{Potential Predictors and Consequences of Recovery Experiences}

\section{Job Stressors and Job Control as Potential Predictors of Recovery Experiences}

We propose that job stressors and job control are associated with recovery experiences. Job stressors are conditions in the work situation that make action regulation more difficult (Frese \& Zapf, 1994). Typical job stressors include workload (time pressure, overtime), role ambiguity, and situational constraints. Job control refers to an individual's discretion to determine the timing and methods of his or her actions (Jackson, Wall, Martin, \& Davids, 1993) and is seen as a resource in the action regulation process (Frese \& Zapf, 1994).

We expect negative relations of job stressors with all four recovery experiences. First, individuals facing job stressors such as time pressure or overtime might find it difficult to detach from work during off-job time. When experiencing job stressors, that is when being confronted with problems and time constraints at work, individuals will be more likely to keep thinking about their job in order to develop solutions for these difficulties. In addition, they will anticipate problems and constraints for the next working day. Empirical evidence suggests that stressful job situations are negatively related to psychological detachment from work during off-job time (Cropley \& Purvis, 2003; Grebner, Semmer, \& Elfering, 2005).

Second, job stressors will be negatively related to relaxation experiences off the job. Research has shown that exposure to stressors is associated with prolonged activation (Brosschot et al., 2005). For example, employees exposed to high job stress showed elevated heart rate and systolic blood pressure after work (Vrijkotte, Van Doornen, \& De Geus, 2000). This higher level of activation caused by job stressors will make it more difficult to arrive at a state of relaxation during off-job time.

Third, job stressors increase fatigue (Zohar, Tzischinski, \& Epstein, 2003) which makes it more difficult to engage in self-regulatory processes (Muraven, Tice, \& Baumeister, 1998). Because activities that result in mastery experiences require a certain degree of effort and self-regulation, job stressors and associated fatigue will make it less likely to experience mastery off the job because it is more difficult to initiate and uphold the respective activities. Accordingly, research showed that job stressors are negatively related to the engagement in active leisure activities such as sport (van Hooff, Geurts, Kompier, \& Taris, 2007).

Job stressors may also decrease the experience of control outside work. For example, high work demands in terms of long work hours or work brought home leaves less time available for leisure activities. This reduces the amount of time the individual can have control over during off-work time. In addition, as mentioned above, job stressors such as time pressure or situational constraints may increase fatigue (Zohar et al., 2003). This may reduce the amount of internal resources available for self-regulation and 
decision making. As a result, the individual may perceive to have lower control during leisure time although the "objective" level of control may be unchanged.

With respect to job control we expect a less uniform pattern of relations. We hypothesize negative relations between job control and psychological detachment and relaxation, and positive relations with mastery and control. Job control means having decision latitude about how to do one's work. This implies that often several options about how to proceed are available. Therefore, one will be more inclined to continue thinking about one's job after work and psychological detachment from work will be more difficult. Similarly, because high job control will stimulate continuous thinking about work during offjob time, relaxation will be more difficult (Brosschot et al., 2005).

Job control enables individuals to take an active approach toward their environment that is reflected in the pursuit of learning activities (Taris \& Kompier, 2005 ) and other proactive behaviors (Frese, Kring, Soose, \& Zempel, 1996). Because of spillover processes across different life domains (Edwards \& Rothbard, 2000) such an active approach should generalize beyond the job domain and result in the enactment of more mastery experiences also during off-job time. Moreover, job control enables individuals to adapt their working strategies and effort expenditure to their current state (Taris et al., 2006). As a consequence, they will be less fatigued after work and will find it less difficult to engage in effortful activities that provide the opportunities for mastery experiences.

Perceiving and experiencing job control will make it more likely that an individual will also try to exert control during off-job time (Meissner, 1971). This means that perceptions of control may "spill over" into the nonwork domain and that experiencing job control will be associated with high levels of experienced control during off-job time.

\section{Coping Styles as Potential Predictors of Recovery Experiences}

We assume that coping styles are related to recovery experiences. Lazarus and Folkman (1984) defined coping as "constantly changing cognitive and behavioral efforts to manage specific external and/or internal demands that are appraised as taxing or exceeding the resources of the person" (p. 141). As coping refers to an individual's attempts to deal with stress, recovery activities can be seen as a way of timedelayed coping with job stress. However, the concepts are not identical. Whereas coping refers to the stressor and to the way individuals deal with it, recovery refers to the way they restore their internal resources.

One categorization of coping styles refers to the differentiation between problem-focused and emotion-focused coping (Lazarus \& Folkman, 1984). Problem-focused coping includes problem-solving behaviors and aims at directly addressing and changing the stressor or other aspects of the situation. Examples of problem-focused coping include active coping, planning, suppression of competing activities, restraint coping, and seeking of instrumental social support (Carver, Scheier, \& Weintraub, 1989). Emotion-focused coping refers to attempts to manage cognitions or emotions directly, without changing the environment. Examples include seeking of emotional social support, positive reinterpretation, acceptance, or denial. Carver et al. (1989) suggested a third category including less successful coping attempts such as focus on emotions and disengagement.

We propose that some, but not all, coping styles are associated with recovery experiences. Specifically, we do not expect a significant relation between problem-focused coping and psychological detachment from work or relaxation. One might argue that seeking solutions for work-related problems or stressors keeps individuals cognitively busy with the problem so that psychological detachment and relaxation would be impeded. However, as problemsolving attempts - probably already during working time-are successful individuals will find it easier to detach themselves from work during off-job time and to relax. We expect that problem-focused coping will show positive, albeit weak, relations with mastery and control. Individuals who actively address stressors might also approach their off-job time more actively. Therefore, they will engage more in activities that provide mastery experiences and will experience more control. With respect to emotion-focused coping we propose a positive relation with all four recovery experiences. As individuals try to manage their cognitions and emotions related to job stress, they will try to seek experiences that give them some relief and improve their positive mood. However, particularly with respect to mastery and control we do not expect strong associations. When it comes to the coping styles that Carver et al. (1989) assumed to be less useful such as disengagement or focus on emotions, the similarity between disengagement and psychological detachment from work is obvious. 
Therefore, we hypothesize a positive relation between disengagement and psychological detachment. With respect to the other three recovery experiences or focus on emotions, we do not propose any significant relations.

\section{Personality as a Potential Predictor of Recovery Experiences}

We propose that some, but not all, of the Big Five personality dimensions are related to recovery experiences. We mainly postulate relations between conscientiousness and emotional stability on the one hand and recovery experiences on the other. Except for one specific relation we do not expect openness to experience, agreeableness, and extraversion to be related to the recovery experiences.

Conscientiousness refers to the extent to which an individual is orderly, self-disciplined, achievementoriented, and reliable (Barrick \& Mount, 1991; Costa \& McCrae, 1992). As conscientious individuals take their jobs seriously, they might also think about their jobs during off-job time. For example, they might reflect about how to do their work during the upcoming workday. It will be more difficult for them to psychologically detach from work and relax during off-work time. At the same time, because they are achievement-oriented, they might not limit their ambitions and self-discipline to their jobs but will also deliberately pursue activities that offer mastery experiences in other life domains.

Emotional stability is an individual's tendency to experience positive emotional states and to show good emotional adjustment to stressful events (Costa \& McCrae, 1992). It is necessary for regulating one's feelings and reactions to stress. Therefore, individuals high in emotional stability will not be bothered much by stressful events encountered at work. They will find it easier to psychologically detach themselves from work and relax during off-job time. As emotionally stable individuals have a more positive approach toward their lives, they will also be more inclined to seek challenging experiences during offjob time. As they are more tolerable toward stressful situations, they will be more willing to accept the demanding nature of activities associated with mastery experiences. Therefore, we hypothesize that emotional stability will be positively related to mastery experiences. In addition, we propose a positive relation between emotional stability and control during off-job time. As time off the job is often associated with additional stressors from the family do- main, individuals high on emotional stability might feel less emotionally affected by these stressors and experience more control.

Openness to experience describes individuals in terms of their creativity, flexibility, and willingness to take risks (Costa \& McCrae, 1992). Because individuals high on openness to experience are curious and search for new learning opportunities, we expect that they will look for opportunities to engage in mastery experiences. Therefore, we hypothesize a positive relation between openness to experience and mastery. We do not expect that openness to experience will be related to any of the three other recovery experiences.

Agreeableness is an individual's tendency to be kind, gentle, and to get along well with others in social settings (Costa \& McCrae, 1992). Therefore, agreeableness should be related to the quality of interpersonal relations during off-job time. However, it should be independent of the four recovery experiences.

Extraversion refers to the extent to which individuals are sociable, assertive, and energized by social interactions (Costa \& McCrae, 1992). We assume that both extravert and introvert individuals have the potential to psychologically detach from work, to relax, to experience mastery and control—although the specific activities by which they reach these experiences may largely differ.

\section{Psychological Well-Being as a Potential Consequence}

As recovery experiences help in unwinding from stress, they will contribute to psychological wellbeing. Here we focus on indicators of (impaired) well-being (e.g., burnout, health complaints, and depressive symptoms), need for recovery, life satisfaction, and sleep.

Unfavorable work situations are associated with impaired psychological well-being such as health complaints (Leitner \& Resch, 2005), burnout (Maslach, Schaufeli, \& Leiter, 2001), or depressive symptoms (Dormann \& Zapf, 2002). We propose that recovery experiences are negatively related to these three indicators of impaired psychological well-being. Work causes strain reactions in the individual that will accumulate and in the long term may develop into health complaints, burnout, or depressive symptoms if they are not reversed (Meijman \& Mulder, 1998). Recovery experiences have the potential to "undo" these strain reactions. 
Therefore, we hypothesize that the recovery experiences are negatively related to health complaints, burnout, and depressive symptoms.

Need for recovery is a specific aspect of impaired well-being and refers to the desire for being temporarily relieved from demands in order to recuperate and to replenish internal resources (Sluiter, Van der Beek, \& Frings-Dresen, 1999). Individuals who chronically experience a high need for recovery feel that the time regularly available for recovery is not sufficient for restoring their internal resources. We hypothesize that recovery experiences are negatively related to need for recovery.

Life satisfaction is a subjective global judgment of a person's quality of life (Diener, Emmons, \& Larson, 1985). Research showed that life satisfaction is not only influenced by top-down processes with personality factors affecting life satisfaction, but also by bottom-up processes with domain-specific satisfactions impacting on life satisfaction (Heller, Watson, \& Ilies, 2004). Individuals with favorable recovery experiences will tend to be more satisfied with their leisure time which in turn will be positively related to life satisfaction. Empirical research suggests that recovery-related experiences are related to life satisfaction (Strauss-Blasche, Ekmekcioglu, \& Marktl, 2002). Therefore, we hypothesize that recovery experiences are positively related to life satisfaction.

Sleep in itself is important for recovery. During sleep, many functions of the organism are restored. In addition, positive recovery experiences should reduce the strain level built up during the working day and should in turn enhance sleep quality. For example, when not sufficiently detaching from work and when keeping thinking about work-related issues, sleep onset and sleep quality will be impaired. Similarly, when relaxation after work is missing, activation will continue which will make it more difficult to fall asleep. Mastery and control will give the individual a feeling of satisfaction and accomplishment that will have a positive impact on sleep quality.

Table 1 summarizes the hypothesized relations between recovery experiences and potential predictors and consequences.

\section{Study 1: Item Generation and Item Review}

Our first study aimed at generating and reviewing items to assess recovery experiences. For all four dimensions (i.e., psychological detachment, relaxation, mastery, control), we generated items that should tap the respective construct. For generating these items, we referred to the description of the constructs as outlined in the introduction of this article, reviewed the literature on recovery and on mood regulation, and used brainstorming techniques to cover a broad range of experiences that reflect these constructs. In total, we generated 47 items, 8 items for psychological detachment, 11 items for relaxation, 16 items for mastery, and 12 items for control.

To examine content validity of these items we provided 16 advanced psychology students with descriptions of the four dimensions and presented the items to them in a random order. Five students $(31.3 \%)$ were in their third year of psychology major, two students $(12.5 \%)$ were in their fourth year of psychology major, five students (31.3\%) were in their fifth year of psychology major, and four participants (25\%) were even more advanced psychology students. The students were asked to classify each item into one of the four dimensions or to an additional "other" category. To reduce the workload for each individual rater, eight raters classified a first set of 23 items, eight other raters classified a second set of 24 items.

All items that were classified to the correct a priori category by at least $75 \%$ of the raters were retained. Based on this decision rule, a total of 35 items remained: 6 items for psychological detachment, 9 items for relaxation, 11 items for mastery, and 9 items for control. Because psychological detachment had only six items remaining, we kept the two original items that did not meet the $75 \%$ decision rule. Both items were correctly classified by $62.5 \%$ of the raters. Thus, we used 37 items for further scale development.

\section{Study 2: Examining Construct Validity}

\section{Sample and Procedure}

Because recovery opportunities and recovery experiences may largely vary between jobs, we sampled employees from a variety of different jobs. To recruit study participants, we first contacted managers of a broad range of different organizations in various business sectors. After the managers expressed interest in participation, we approached the employees either by mail or in person at their workplace, presented the study and asked for participation.

We contacted a total of 1409 persons by mail and 420 persons directly at their workplace. All these potential participants were provided with the survey material and a cover letter describing the study. Per- 
Table 1

Hypothesized Relations Between Recovery Experiences, Potential Predictors, and Potential Outcomes

\begin{tabular}{|c|c|c|c|c|}
\hline Variables & $\begin{array}{c}\text { Psychological } \\
\text { detachment }\end{array}$ & Relaxation & Mastery & Control \\
\hline \multicolumn{5}{|l|}{ Job situation variables } \\
\hline Job stressors & - & - & - & - \\
\hline Job control & - & - & + & + \\
\hline \multicolumn{5}{|l|}{ Coping } \\
\hline Problem-focused coping & 0 & 0 & + & + \\
\hline Emotion-focused coping & + & + & + & + \\
\hline Other coping strategies & + & 0 & 0 & 0 \\
\hline \multicolumn{5}{|l|}{ Personality } \\
\hline Agreeableness & 0 & 0 & 0 & 0 \\
\hline Openness & 0 & 0 & + & 0 \\
\hline Extraversion & 0 & 0 & 0 & 0 \\
\hline Conscientiousness & - & - & + & 0 \\
\hline Emotional stability & + & + & + & + \\
\hline \multicolumn{5}{|l|}{ Psychological well-being } \\
\hline Health complaints & - & - & - & - \\
\hline Burnout & - & - & - & - \\
\hline Depressive symptoms & - & - & - & - \\
\hline Need for recovery & - & - & - & - \\
\hline Life satisfaction & + & + & + & + \\
\hline Sleep problems & - & - & - & - \\
\hline
\end{tabular}

Note. $\quad+=$ hypothesized positive relation; $-=$ hypothesized negative relation; $0=$ no relation hypothesized.

sons approached by mail also received a prestamped envelope addressed to the researchers. Surveys completed by the persons contacted directly were collected by a member of the research team. From the persons contacted by mail, 755 questionnaires were returned (response rate of $53.6 \%$ ). From the persons directly contacted, 236 questionnaires were returned (response rate of 56.2\%). A total of 991 questionnaires were returned, for an overall response rate of $54.6 \%$.

Most participants were women (71\%). Participants' mean age was 38.3 years $(S D=12.3)$, mean job tenure was 15.1 year $(S D=11.2)$. Among all participants, $24.0 \%$ had a supervisory position. Of the total sample, $58.0 \%$ had children with an average of 1.8 children. Participants came from a broad variety of private and public organizations with $26.7 \%$ working in the public administration, $18.3 \%$ as teachers in schools, $11.0 \%$ in call centers, $9.6 \%$ in hospitals, $9.3 \%$ in nursing homes, $6.0 \%$ in public relation agencies, $4.5 \%$ in retail companies, and $4.1 \%$ in insurance organizations. The remaining participants came from a manufacturing company, banks, hotels, travel agencies, and other service organizations. The percentage of participants working irregular hours was $18.6 \%$. Data on psychological detachment from $N=148$ teachers participating in this study were also used in another study (Sonnentag \& Kruel, 2006).

\section{Measures}

The survey included a total of 37 items assessing recovery experiences (psychological detachment: 8 items, relaxation: 9 items, mastery: 11 items; control: 9 items). Participants were asked to respond to the items with respect to their free evenings (e.g., "During time after work, I kick back and relax") on a 5-point scale from1 (I do not agree at al) to 5 (I fully agree). Moreover, we assessed gender, age, number of children, job tenure and occupation. In a subsample $(N=271)$, we additionally measured a range of other variables to examine the nomological net of the recovery experience measures (see Study 3).

\section{Strategy for Analyzing Data}

To examine the construct validity of our recovery experience measures, we used a cross-validation approach and randomly split the overall sample $(N=$ 991) into two subsamples. Because of missing values, sample size in each of the two subsamples was $N=465$. We used the first subsample for finding the best-fitting model (calibration sample) and then cross-validated this model with the second subsample (cross-validation sample). 


\section{Results}

By using calibration sample data, we submitted a covariance matrix based on the 37 items derived from Study 1 to a set of Confirmatory Factor Analyses. First, we separately fitted single-factor models for each of the four constructs and then fitted two-factor models for all possible pairs of constructs (relaxation vs. mastery, relaxation vs. psychological detachment, relaxation vs. control etc.). Subsequently, we deleted items that (a) had very high cross-loading on another than the intended factor, (b) showed high acrossfactor correlated measurement errors, and (c) low loadings on the intended factor (modification indices exceeding 25.00 and factor loadings below 0.50). This procedure resulted in a set of 20 items. We conducted a Confirmatory Factor Analysis with these 20 items by specifying a four-factor structure. Analysis showed a reasonable, although not very good fit $\left(\chi^{2}=631.13 ; d f=164 ; \mathrm{GFI}=.88 ; \mathrm{NNFI}=.96\right.$; $\mathrm{CFI}=.95 ;$ RMSEA $=.078 ;$ SRMR $=.055)$. To arrive at a better model fit and at shorter, more parsimonious scales, we again removed some items based on the above specified criteria. The final model comprised 16 items with an acceptable fit $\left(\chi^{2}=\right.$ $317.15 ; d f=98 ; \mathrm{GFI}=.92 ; \mathrm{NNFI}=.97 ; \mathrm{CFI}=.97$; RMSEA $=.069$; SRMR $=.045)$. We compared this four-factor model with alternative one-factor, twofactor, and three-factor models. Table 2 shows the fit indices of the best-fitting two-factor models and bestfitting three-factor models. The four-factor model showed a significantly better fit than the one-factor model $\left(\Delta \chi^{2}=2131.66 ; \Delta d f=6 ; p<.001\right)$, all two-factor models $\left(\Delta \chi^{2} \geq 1713.31 ; \Delta d f=5 ; p<\right.$ $.001)$, and all three-factor models $\left(\Delta \chi^{2} \geq 546.50\right.$; $\Delta d f=3 ; p<.001)$.

In the next step, we further examined this factor structure with the cross-validation sample. We first tested a model with the 20 items used in the calibration sample. This 20-item model resulted in a reasonable but slightly worse fit than analysis with the calibration sample $\left(\chi^{2}=705.82 ; d f=164\right.$; GFI $=$ .87 ; NNFI $=.95 ;$ CFI $=.96$; RMSEA $=.084$; SRMR $=.060)$. The four-factor model with 16 items resulted in an acceptable fit $\left(\chi^{2}=403.60 ; d f=98\right.$; $\mathrm{GFI}=.90 ; \mathrm{NNFI}=.96 ; \mathrm{CFI}=.96 ; \mathrm{RMSEA}=.082 ;$ SRMR $=.049)$ although the RMSEA slightly deviated from the recommended value of .080. Again, this four-factor model showed a better fit than the one-factor model $\left(\Delta \chi^{2}=2597.16 ; \Delta d f=6 ; p<\right.$ .001), all two-factor models $\left(\Delta \chi^{2} \geq 2033.05 ; \Delta d f=\right.$ $5 ; p<.001)$, and all three-factor models $\left(\Delta \chi^{2} \geq\right.$ 704.46; $\Delta d f=3 ; p<.011$ ).

Table 3 displays items wordings, factor loadings, and alphas for both subsamples. Taken together, the confirmatory factor analyses showed that the four recovery experience scales represent distinct constructs and show good reliability. Table 4 shows that the correlations among the latent variables were moderate. Only relaxation and control were rather highly correlated. For further analyses we used the unweighted means of all scale items as indicators for the respective scales.

Table 2

Goodness of Fit Statistics

\begin{tabular}{|c|c|c|c|c|c|c|c|}
\hline & $x^{2}$ & $d f$ & GFI & NNFI & CFI & RMSEA & SRMR \\
\hline \multicolumn{8}{|l|}{ Calibration sample } \\
\hline One-factor model & 2448.80 & 104 & .60 & .72 & .75 & .22 & .15 \\
\hline Best fitting two-factor model ${ }^{\mathrm{a}}$ & 2030.46 & 103 & .65 & .77 & .80 & .20 & .14 \\
\hline Best fitting three-factor model ${ }^{\mathrm{b}}$ & 863.65 & 101 & .81 & .91 & .92 & .13 & .06 \\
\hline Four-factor model & 317.15 & 98 & .92 & .97 & .97 & .07 & .05 \\
\hline \multicolumn{8}{|l|}{ Cross-validation sample } \\
\hline One-factor model & 3000.76 & 104 & .55 & .67 & .71 & .25 & .16 \\
\hline Best fitting two-factor model ${ }^{\mathrm{c}}$ & 2436.65 & 103 & .60 & .74 & .78 & .22 & .18 \\
\hline Best fitting three-factor model ${ }^{\mathrm{b}}$ & 1108.06 & 101 & .77 & .89 & .91 & .15 & .07 \\
\hline Four-factor model & 403.60 & 98 & .90 & .96 & .96 & .08 & .05 \\
\hline
\end{tabular}

Note. $\quad$ GFI = goodness-of-fit index; NNFI = nonnormed fit index; CFI = comparative fit index; RMSEA $=$ root mean square error of approximation; SRMR $=$ standardized root mean square residual

${ }^{a}$ Psychological detachment and relaxation items loading on the first factor and mastery and control items loading on the second factor. ${ }^{\mathrm{b}}$ Relaxation and control items loading on the first factor, psychological detachment items loading on the second, and mastery items loading on the third factor. ${ }^{\mathrm{c}}$ Relaxation and control items loading on the first factor and psychological detachment and mastery items loading on the second factor. 
Table 3

Factor Loadings and Alphas for Recovery Experience Measures

\begin{tabular}{|c|c|c|c|c|}
\hline Item & $\begin{array}{l}\text { Psychological } \\
\text { detachment }\end{array}$ & Relaxation & Mastery & Control \\
\hline I forget about work. & $0.96(0.05)$ & & & \\
\hline \multirow[t]{2}{*}{ I don't think about work at all. } & $0.88(0.05)$ & & & \\
\hline & $0.91(0.05)$ & & & \\
\hline \multirow[t]{2}{*}{ I distance myself from my work. } & $0.85(0.04)$ & & & \\
\hline & $0.79(0.04)$ & & & \\
\hline \multirow[t]{2}{*}{ I get a break from the demands of work. } & $0.69(0.04)$ & & & \\
\hline & $0.56(0.03)$ & & & \\
\hline \multirow[t]{2}{*}{ I kick back and relax. } & & $0.74(0.04)$ & & \\
\hline & & $0.66(0.03)$ & & \\
\hline \multirow[t]{2}{*}{ I do relaxing things. } & & $0.52(0.03)$ & & \\
\hline & & $0.75(0.04)$ & & \\
\hline \multirow[t]{2}{*}{ I use the time to relax. } & & $0.70(0.03)$ & & \\
\hline & & $0.79(0.04)$ & & \\
\hline \multirow[t]{2}{*}{ I take time for leisure. } & & $0.61(0.03)$ & & \\
\hline & & $0.64(0.03)$ & & \\
\hline \multirow[t]{2}{*}{ I learn new things. } & & & $0.60(0.04)$ & \\
\hline & & & $0.65(0.04)$ & \\
\hline \multirow{2}{*}{ I seek out intellectual challenges. } & & & $0.79(0.04)$ & \\
\hline & & & $0.72(0.03)$ & \\
\hline \multirow[t]{2}{*}{ I do things that challenge me. } & & & $0.64(0.04)$ & \\
\hline & & & $0.66(0.03)$ & \\
\hline \multirow[t]{2}{*}{ I do something to broaden my horizons. } & & & $0.60(0.03)$ & \\
\hline & & & $0.67(0.03)$ & \\
\hline \multirow{3}{*}{$\begin{array}{l}\text { I feel like I can decide for myself what } \\
\text { to do. }\end{array}$} & & & & \\
\hline & & & & $0.79(0.05)$ \\
\hline & & & & $0.58(0.03)$ \\
\hline \multirow[t]{2}{*}{ I decide my own schedule. } & & & & $0.60(0.03)$ \\
\hline & & & & $0.86(0.04)$ \\
\hline \multirow{2}{*}{$\begin{array}{l}\text { I determine for myself how I will spend } \\
\text { my time. }\end{array}$} & & & & $0.69(0.03)$ \\
\hline & & & & $0.68(0.03)$ \\
\hline \multirow{2}{*}{$\begin{array}{l}\text { I take care of things the way that I want } \\
\text { them done. }\end{array}$} & & & & $0.67(0.04)$ \\
\hline & & & & $0.48(0.03)$ \\
\hline \multirow[t]{2}{*}{ Cronbach's alpha } & .84 & .85 & .79 & .85 \\
\hline & .85 & .85 & .85 & .85 \\
\hline
\end{tabular}

Note. Factor loadings with standard errors in parentheses. Upper rows give estimates from the calibration sample, lower rows give estimates from the cross-validation sample.

\section{Study 3: Examining the Nomological Net}

Study 3 aimed at analyzing the nomological net of the four recovery experience measures by examining their relations with potential predictors and consequences.

\section{Sample}

Two subsamples from Study 2 participated in this study. Subsample 1 comprised 134 persons (47\% men). Mean age was 40.9 years $(S D=10.4)$; mean job tenure was 18.4 years $(S D=11.2)$. About a third $(32.1 \%)$ of the first subsample held a supervisory position. Of all participants in this subsample, 53\% had children with an average of 2.0 children. Most participants came from local public administration organizations (86.8\%). The other participants worked in travel agencies $(7.8 \%)$ and retail organizations (5.4\%). Subsample 2 comprised 137 persons $(60.6 \%$ men) with a mean age of 38.6 years $(S D=9.6)$ and mean job tenure of 15.3 years $(S D=$ 9.4). Of these 137 persons, $30 \%$ worked in a supervisory position. About a half $(52.6 \%)$ of the participants had children with an average of 1.8 children. Participants worked in the field of local public administration (79.9\%), in a technical service company (7.5\%), travel agencies $(7.6 \%)$, and retail organizations $(6.0 \%)$. 
Table 4

Correlations Between the Latent Variables

\begin{tabular}{lcccc}
\hline & $\begin{array}{c}\text { Psychological } \\
\text { detachment }\end{array}$ & Relaxation & Mastery & Control \\
\hline Psychological & & & & \\
$\quad$ detachment & & .42 & .19 & .41 \\
Relaxation & .46 & & .30 & .71 \\
Mastery & .21 & .34 & & .28 \\
Control & .37 & .65 & .25 & \\
\hline
\end{tabular}

Note. Correlations above the diagonal are from the calibration sample. Correlations below the diagonal are from the cross-validation sample. All correlations are significant at $p<.01$.

There were no mean differences in the four recovery experience scales, neither between these two subsamples nor between these two subsamples and participants who only participated in Study 2. Overall, also the correlational patterns did not differ between the various subsamples. However, the correlation between relaxation and control in the two subsamples was somewhat higher, $r=.64, N=271$, than in the larger sample (excluding the two subsamples), $r=$ $.51, N=719, z=2.72, p<.01$.

\section{Measures}

In both subsamples we assessed job stressors and job control. We additionally measured coping and personality variables in subsample 1 , and psychological well-being in subsample 2 . We decided not to measure all variables in both subsamples in order not to impose heavy time demands on our participants when completing the surveys. Table 5 displays means, standard deviations, correlations, and alphas for all study variables. Higher scores indicate a higher degree of the phenomenon under study.

Work situation variables. We assessed job stressors and job control with measures developed by Semmer (1984; cf. Zapf, 1993). To cover different job stressors, we assessed time pressure, role ambiguity, situational constraints, and hours of overtime. We measured time pressure with five items (e.g., "How often is a fast pace of work required of you?") using a 5-point scale from 1 (almost never) to 5 (very often). For assessing role ambiguity we used five items (e.g., "How often do you receive contradictory instructions from different supervisors?") with a 5-point scale from 1 (almost never) to 5 (very often). We measured situational constraints with five items describing two contrasting workplaces (e.g., "Person
A must spend a lot of time in order to get information and/or materials to pursue his or her work activity." "Person B always has the necessary information and/or materials at his or her disposal."). On a 5-point scale from 1 ( $m y$ job is exactly like that of Person $B$ ) to 5 (my job is exactly like that of Person A), participants had to indicate which of the descriptions most adequately characterized their work situation. We assessed hours of overtime with one single item. We measured job control with five items (e.g., "Can you yourself decide on which way to carry out your work?") using a 5-point scale from 1 (very little) to 5 (to a very large extent).

Coping. We assessed coping in subsample 1 with the COPE measures (Carver et al., 1989) in their German version (Vollrath \& Torgersen, 2000). We measured four coping strategies representing problem-focused coping (active coping, planning, restraint coping, use of instrumental social support), two coping strategies representing emotion-focused coping (denial, use of emotional social support), and three other coping attempts (focus on emotions, behavioral disengagement, mental disengagement). All coping strategies were assessed with four items each on a 4-point scale from 1 (never) to 4 (often).

Personality. We assessed the Big Five personality factors in subsample 1 with the German Version (Lang, Lüdtke, \& Asendorpf, 2001) of the Big Five Inventory (John \& Srivastava, 1999) and measured conscientiousness with nine items, emotional stability with seven items, openness to experience with 10 items, extraversion with eight items, and agreeableness with eight items on 5-point scales from1 (not at all) to 5 (very much).

Psychological well-being. In subsample 2 we assessed health complaints, burnout, depressive symptoms, need for recovery, life satisfaction, and sleep problems as indicators of (poor) psychological wellbeing. We measured health complaints with 12 items from the General Health Questionnaire (Goldberg, 1972; e.g., "Did you experience a lack of selfconfidence during the last two weeks?") on a 4-point scale from 1 (not at all) to 4 (much more than usual). We measured burnout with the Oldenburg Burnout Inventory (Demerouti, Bakker, Nachreiner, \& Schaufeli, 2001) and assessed emotional exhaustion (e.g., "After my work I usually feel worn out and weary") and disengagement (e.g., "I usually talk about my work in a derogatory way") with eight items each on a 4-point scale from1 (fully disagree) to 4 (fully agree). We assessed depressive symptoms with eight items developed by Mohr (1986; e.g., "I am often in a sad mood"). We used a 7-point re- 
sponse scale from 1 (almost always) to 7 (never) that was reversed for correlational analysis. Need for recovery was measured with 11 items (van Veldhoven \& Broersen, 2003; e.g., "At the end of a working day I am really feeling worn-out") using a 4-point scale from 1 (never) to 4 (always). For measuring life satisfaction we used five items from the Satisfaction With Life Scale (Diener et al., 1985; e.g., "In most ways my life is close to my ideals") to be answered on a 7-point scale from 1 (fully disagree) to 7 (fully agree). We measured sleep problems with nine items from the Pittsburgh Sleep Quality Index (Buysse, Reynolds, Monk, Berman, \& Kupfer, 1989) using a 4-point scale from 1 (not at all) to 4 (three times or more per week).

\section{Results}

Table 5 shows the relations between all study variables. Time pressure was negatively related to all recovery experience variables with the exception of mastery. Role ambiguity and situational constraints were negatively related to psychological detachment and control. Hours of overtime were negatively related to psychological detachment and relaxation but not to mastery or control. Job control was positively related to control during off-job time. Taken together, analysis largely confirmed our hypotheses for job stressors and partially for job control.

Correlations between coping and recovery experiences were low and mostly nonsignificant. There were some significant correlations, namely between active coping and the experience of mastery and control. Restraint coping was positively related to psychological detachment and mastery. Seeking instrumental social support showed a positive relation with relaxation and control. Seeking emotional social support was negatively related to psychological detachment and positively related to relaxation and control. Mental disengagement was positively related to relaxation. These generally low correlations between coping and recovery experiences provided partial support for our hypotheses and overall demonstrated that there is only limited overlap between the way an individual responds to a stressors (i.e., coping) and how he or she experiences recovery off the job.

Most correlations between the personality variables and the recovery experience constructs were low and nonsignificant indicating that personality seems not to be a core predictor of how individuals experience their off-job time. Openness to experience and extraversion were positively related to mastery. Emotional stability was positively correlated with psychological detach- ment, mastery, and control. Overall, most of our hypotheses on the relation between personality and recovery experiences were supported.

We found moderate relations between recovery experiences and well-being measures. Psychological detachment and control showed negative relations with health complaints, emotional exhaustion, depressive symptoms, need for recovery, and sleep problems. Relaxation showed negative relations with health problems, emotional exhaustion, need for recovery, and sleep problems. Mastery was negatively related to emotional exhaustion, depressive symptoms, and need for recovery. All recovery experience measures showed positive relations with life satisfaction. Except for the burnout dimension disengagement, the overall pattern of correlations supported our hypotheses.

\section{Overall Discussion}

In this article we presented measures for assessing recovery experiences. Confirmatory factor analyses showed that four distinct recovery experiences can be differentiated (psychological detachment, relaxation, mastery, control). The scales have good internal consistencies and are short so that they can be used in future research without putting high time demands on study participants.

Correlational analyses showed that job stressors were related to three of the four recovery experiences. The rather high negative correlation between time pressure and psychological detachment is in line with earlier research (Sonnentag \& Bayer, 2005) suggesting that time pressure and the associated high workload make it particularly difficult to switch off from work during leisure time. Relaxation was related to aspects of quantitative workload, but not to other job stressors. It might be that particularly prolonged activation because of time pressure and overtime hinders relaxation during off-job time, whereas other job stressors do not necessarily result in prolonged activation but impede other aspects of recovery by depleting self-regulatory resources (Sonnentag \& Jelden, 2005). Unexpectedly, job stressors were not related to mastery experiences. It might be that individuals do not react uniformly to job stressors. Some individuals might feel that job stressors hinder them to enjoy mastery, whereas others might deliberately try to counteract the negative effects of job stressors by engaging in activities that provide the opportunity for positive experiences and mastery.

Job control was not related to psychological detachment, relaxation, or mastery. One might specu- 
Table 5

Means, Standard Deviations, Zero-Order Correlations, and Alphas of Study 3 Variables

\begin{tabular}{|c|c|c|c|c|c|c|c|c|c|c|c|}
\hline & $M$ & $S D$ & 1 & 2 & 3 & 4 & 5 & 6 & 7 & 8 & 9 \\
\hline \multicolumn{12}{|l|}{ Recovery experiences } \\
\hline 1. Psychological detachment ${ }^{\mathrm{a}, \mathrm{d}}$ & 3.00 & 0.97 & .89 & & & & & & & & \\
\hline 2. Relaxation ${ }^{\mathrm{a}, \mathrm{d}}$ & 3.29 & 0.80 & .33 & .87 & & & & & & & \\
\hline 3. Mastery ${ }^{\mathrm{a}, \mathrm{d}}$ & 3.04 & 0.71 & .16 & .24 & .82 & & & & & & \\
\hline 4. Control ${ }^{\mathrm{a}, \mathrm{d}}$ & 3.70 & 0.77 & .33 & .64 & .30 & .87 & & & & & \\
\hline \multicolumn{12}{|l|}{ Job situation variables } \\
\hline 5. Time pressure ${ }^{\mathrm{a}, \mathrm{d}}$ & 3.03 & 0.96 & -.49 & -.31 & -.04 & -.32 & .89 & & & & \\
\hline 6. Role ambiguity ${ }^{\mathrm{a}, \mathrm{d}}$ & 2.40 & 0.66 & -.19 & -.03 & -.02 & -.21 & .33 & .69 & & & \\
\hline 7. Situational constraints ${ }^{\mathrm{a}, \mathrm{d}}$ & 2.59 & 0.69 & -.15 & -.11 & -.08 & -.21 & .34 & .57 & .70 & & \\
\hline 8. Hours of overtime ${ }^{a}$ & 4.51 & 6.06 & -.23 & -.18 & -.05 & -.11 & .42 & .00 & -.01 & - & \\
\hline 9. Job control ${ }^{\mathrm{a}, \mathrm{d}}$ & 3.68 & 0.66 & .11 & .02 & .08 & .16 & .07 & -.29 & -.20 & .29 & .77 \\
\hline \multicolumn{12}{|l|}{ Coping } \\
\hline 10. Active coping ${ }^{\mathrm{b}, \mathrm{e}}$ & 2.84 & 0.54 & -.03 & .12 & .26 & .18 & .08 & -.10 & -.12 & .15 & .19 \\
\hline 11. Planning $\mathrm{b}, \mathrm{e}$ & 2.90 & 0.56 & .10 & .02 & .14 & .13 & .10 & -.04 & .09 & .21 & .27 \\
\hline 12. Restraint coping ${ }^{\mathrm{b}, \mathrm{e}}$ & 2.69 & 0.91 & .17 & .16 & .02 & .17 & .11 & .01 & .15 & .03 & .05 \\
\hline \multicolumn{12}{|l|}{ 13. Instrumental social } \\
\hline support $^{\mathrm{b}, \mathrm{e}}$ & 2.48 & 0.67 & -.07 & .33 & .09 & .18 & -.05 & -.06 & -.09 & -.02 & .07 \\
\hline 14. Emotional social support ${ }^{\mathrm{b}, \mathrm{e}}$ & 2.56 & 0.74 & -.19 & .33 & .07 & .18 & .03 & .01 & .05 & .03 & .06 \\
\hline 15. Denial ${ }^{\mathrm{b}, \mathrm{e}}$ & 1.24 & 0.36 & -.00 & .13 & .05 & .07 & -.04 & .12 & -.04 & -.19 & -.18 \\
\hline 16. Focus on emotions ${ }^{\mathrm{b}, \mathrm{e}}$ & 2.27 & 0.85 & -.07 & .16 & .03 & .13 & .00 & .18 & .12 & -.19 & -.17 \\
\hline \multicolumn{12}{|l|}{ 17. Behavioral } \\
\hline disengagement $^{\mathrm{b}, \mathrm{e}}$ & 1.49 & 0.45 & -.02 & -.05 & -.14 & -.10 & .02 & .15 & .11 & -.19 & -.23 \\
\hline 18. Mental disengagement ${ }^{\mathrm{b}, \mathrm{e}}$ & 2.24 & 0.56 & -.06 & .22 & -.02 & .06 & .03 & .28 & .20 & -.27 & -.25 \\
\hline \multicolumn{12}{|l|}{ Personality } \\
\hline 19. Agreeableness ${ }^{\mathrm{b}, \mathrm{d}}$ & 3.64 & 0.52 & .13 & -.02 & .06 & .07 & -.14 & -.16 & -.11 & .05 & .11 \\
\hline 20. Openness ${ }^{\mathrm{b}, \mathrm{d}}$ & 3.46 & 0.60 & .03 & .04 & .35 & .06 & .08 & .00 & .10 & .20 & .18 \\
\hline 21. Extraversion ${ }^{\mathrm{b}, \mathrm{d}}$ & 3.45 & 0.64 & .06 & .07 & .22 & .15 & .04 & -.09 & -.11 & .22 & .19 \\
\hline 22. Conscientiousness ${ }^{\mathrm{b}, \mathrm{d}}$ & 3.73 & 0.60 & -.09 & -.12 & .12 & .07 & -.04 & -.06 & -.03 & .02 & .14 \\
\hline \multicolumn{12}{|l|}{ Psychological well-being } \\
\hline 23. Emotional stability ${ }^{\mathrm{b}, \mathrm{d}}$ & 3.30 & 0.61 & .30 & .12 & .21 & .24 & -.18 & -.24 & -.24 & .14 & .22 \\
\hline 24. Health complaints ${ }^{\mathrm{c}, \mathrm{e}}$ & 2.01 & 0.54 & -.47 & -.24 & -.15 & -.25 & .32 & .40 & .41 & .08 & -.32 \\
\hline 25. Emotional exhaustion ${ }^{\mathrm{c}, \mathrm{e}}$ & 2.41 & 0.57 & -.56 & -.34 & -.25 & -.41 & .44 & .33 & .45 & .06 & -.22 \\
\hline 26. Disengagement ${ }^{\mathrm{c}, \mathrm{e}}$ & 2.05 & 0.54 & -.16 & -.09 & -.11 & -.13 & .02 & .40 & .42 & -.09 & -.47 \\
\hline 27. Depressive symptoms ${ }^{\mathrm{c}, \mathrm{f}}$ & 2.81 & 1.04 & -.40 & -.16 & -.18 & -.18 & .16 & .44 & .42 & -.05 & -.35 \\
\hline 28. Need for recovery ${ }^{\mathrm{c}, \mathrm{e}}$ & 2.19 & 0.58 & -.52 & -.27 & -.24 & -.38 & .34 & .34 & .44 & .08 & -.18 \\
\hline 29. Life satisfaction ${ }^{\mathrm{c}, \mathrm{f}}$ & 4.58 & 1.28 & .37 & .22 & .24 & .21 & -.22 & -.40 & -.37 & -.06 & .21 \\
\hline 30. Sleep problems ${ }^{\mathrm{c}, \mathrm{e}}$ & 1.79 & 0.54 & -.25 & -.18 & -.02 & -.21 & .12 & .26 & .29 & -.04 & -.21 \\
\hline
\end{tabular}

Note. Alphas are displayed on the diagonal.

${ }^{\mathrm{a}} N=267-271$; all correlations $r \geq|.12|$ are significant with $p<.05 .{ }^{\mathrm{b}} N=134$; all correlations $r \geq|.17|$ are significant with $p<$ .05 . ${ }^{\mathrm{c}} N=137$; all correlations $r \geq|.17|$ are significant with $p<.05 .{ }^{\mathrm{d}}$ Range: 1 to 5 . ${ }^{\mathrm{e}}$ Range 1 to $4 .{ }^{\mathrm{f}}$ Range 1 to 7 .

late that the association between job control and recovery experiences is a more complex one. For example, in jobs with high control there might exist some recovery opportunities even during working time (Taris et al., 2006), in turn making detachment and relaxation at home more likely. However, as job control often implies the possibility and the necessity to make decisions, at the same time recovery off the job might be impaired.

Correlations between coping measures and recovery experiences were generally low and mostly nonsignificant. One reason for the low correlations might be that our coping measures were rather broad and did not focus on coping with job-related matters whereas the recovery experiences, particularly psychological detachment, more closely referred to jobrelated recovery. However, problem-focused coping was related to the recovery experience control which might reflect a person's general tendency to actively approach everyday situations and problems. Interestingly, both social support measures were related to relaxation. It might be that social support is particularly helpful in calming down after work. It will be an interesting question for future research to examine in more detail if social support at work or social support at home is more closely related to relaxation. 
Table 5

Continued

\begin{tabular}{lllllllllllllllllllll}
\hline 10 & 11 & 12 & 13 & 14 & 15 & 16 & 17 & 18 & 19 & 20 & 21 & 22 & 23 & 24 & 25 & 26 & 27 & 28 & 29 & 30
\end{tabular}

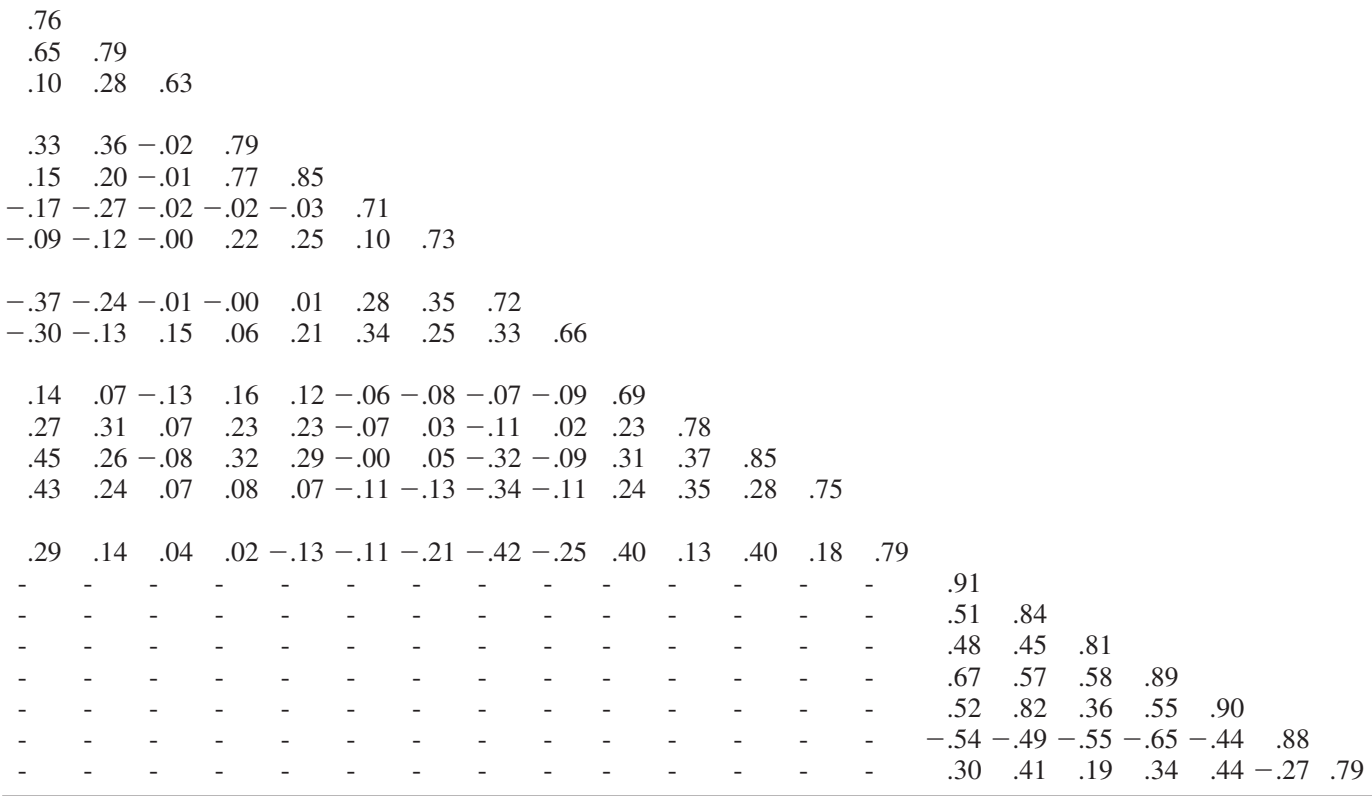

As predicted, correlations between personality and recovery experience measures were generally low. The significant correlations between emotional stability and the recovery experiences might indicate that poor recovery from work may partly result from low emotional stability or negative affectivity. However, the correlations were only moderate in size suggesting that poor recovery experiences do not only reflect low emotional stability.

Recovery experiences were related to most of the indicators of psychological well-being. These findings might indicate that poor recovery harms psychological well-being. It might also be that individuals suffering from impaired well-being are less likely to enjoy positive recovery experiences.
Among all four recovery experiences, psychological detachment showed the strongest relations with impaired well-being. This finding might indicate that psychological detachment is the most relevant recovery experience. Overall, our analyses demonstrated that recovery experiences, particularly psychological detachment and control were associated with job stressors and well-being. Although any causal inferences from these cross-sectional findings are premature, our study suggests that it is promising to examine the relations between an unfavorable work situation, poor recovery and impaired well-being in more detail. For example, one might speculate that job stressors lead to poor recovery experiences that in 
turn negatively affect well-being (cf. Geurts \& Sonnentag, 2006).

\section{Limitations}

Our studies have some limitations. First, the four recovery experience measures might not comprise all potentially relevant recovery experiences. One might argue that the general affective valence of a recovery activity represents an important aspect of any recovery experience. That is, the potential of a recovery experience to enhance positive emotions might be particularly important (Fredrickson, 2000). Instead of conceptualizing positive affective valence as a separate recovery experience, we think that finding pleasure in off-job activities is a higher-order concept that cannot be easily differentiated from other recovery experiences. Empirical studies on mood regulation suggest that pleasure is associated with experiences such as relaxation or distraction (Thayer et al., 1994; Totterdell \& Parkinson, 1999).

Similarly, the degree to which a recovery activity provides opportunities for social contact and connectedness might be important. Scholars in the field of social psychology have argued that social inclusion is one core striving of human beings (Baumeister \& Leary, 1995). Also with respect to recovery processes, the relevance of social activities has been demonstrated (Fritz \& Sonnentag, 2005). Therefore, future research may put more emphasis on the social embeddedness of recovery. However, when doing so, we suggest keeping in mind that social contact and connectedness might not only be a source of social support and recovery, but potentially also of social undermining and interpersonal conflict.

The correlations between the latent variables relaxation and control were rather high. Therefore, one might question if relaxation and control represent two distinct constructs. However, confirmatory factor analyses showed that the 4-factor model fitted the data better than a 3-factor model. In addition, although the correlational patterns of the relaxation and the control scale with other variables showed similarities, they were far from being identical suggesting that it makes sense to differentiate between relaxation and control.

Finally, it has to be noted that the sample sizes in Study 3 were relatively small. Therefore, particularly the nonsignificant correlations should be interpreted with great caution. A replication with a larger sample is clearly desirable.

\section{Suggestions for Future Research and Potential Applications}

The correlations found between low psychological detachment and impaired well-being might suggest that psychological detachment from work during offjob time is crucial for protecting one's well-being. However, this conclusion is premature-not only because our data do not warrant any causal interpretation. Not detaching from work does not necessarily imply that thinking about work is negative per se. Positively reflecting about one's work (e.g., thinking about a recent success or about an inspiring goal) might even improve well-being (Fritz \& Sonnentag, 2005). It can be promising for future research to assess in greater detail the type and quality of workrelated thoughts during off-job time.

Our relaxation items refer to experiences that can be initiated both by deliberate relaxation exercises (e.g., progressive muscle relaxation) and by other activities such as taking a walk or listening to calm music. It could be interesting for future research to differentiate between purposeful relaxation practices and other experiences that have a strong relaxational component and to explore their role in the recovery process.

In Study 3, we focused on zero-order correlations between recovery experiences and a range of other variables. Future research may examine more complex patterns of relations. For example, recovery experiences might be conceptualized as a moderator in the relation between job stressors and impaired wellbeing with poor recovery experiences increasing the association between job stressors and poor wellbeing. Moreover, personality might be examined as a moderator in the relations between job stressors and recovery experiences. For example, one could argue the job stressors are particularly related to poor psychological detachment in persons low on emotional stability.

One important application would be to use the recovery measures in longitudinal research. Future studies should examine if recovery experiences can predict changes in well-being and job performance over time. Moreover, as our scales are short, they can also be easily adapted for use in diary studies. Such studies could examine recovery processes at the day level and could therefore shed more light onto shorter-term processes related to the maintenance of positive mood and performance capability. For example, the recovery experience scales can be applied when extending research on episodic models of performance (Beal, Weiss, Barros, \& MacDermid, 2005). It 
would be particularly interesting to examine if recovery experiences can explain day-level variations in performance. Another option could be to integrate the recovery experience measures in studies on physiological processes related to activation and unwinding (Semmer, Grebner, \& Elfering, 2004; Sonnentag \& Fritz, 2006).

\section{Conclusion}

To conclude, the recovery experience questionnaire offers an economic and reliable approach to assess individuals' unwinding and recuperation processes. It can be a useful tool in the endeavor to better understand the mechanisms underlying the effects of job stressors on the individual. In addition, and maybe more importantly, it can serve as an instrument that identifies experiences helpful in protecting individuals' well-being and performance capability.

\section{References}

Bandura, A. (1997). Self-efficacy: The exercise of control. New York: Freeman.

Barrick, M. R., \& Mount, M. K. (1991). The big five personality dimensions and job performance: A metaanalysis. Personnel Psychology, 44, 1-26.

Baumeister, R. F., \& Leary, M. R. (1995). The need to belong: Desire for interpersonal attachments as a fundamental human motivation. Psychological Bulletin, 117, 497-529.

Beal, D. J., Weiss, H. M., Barros, E., \& MacDermid, S. M. (2005). An episodic process model of affective influences on performance. Journal of Applied Psychology, 90, 1054-1068s.

Brosschot, J. F., Pieper, S., \& Thayer, J. F. (2005). Expanding stress theory: Prolonged activitation and perseverative cognition. Psychoneuroendocrinology, 30, 1043 1049.

Burger, J. M. (1989). Negative reactions to increases in perceived personal control. Journal of Personality and Social Psychology, 56, 246-256.

Buysse, D. J., Reynolds, C. F., Monk, T. H., Berman, S. R., \& Kupfer, D. J. (1989). Pittsburgh sleep quality index (PSQI). Psychiatry Research, 28, 193-213.

Carver, C. S., Scheier, M. F., \& Weintraub, J. K. (1989). Assessing coping strategies: A theoretically based approach. Journal of Personality and Social Psychology, 56, 267-283.

Costa, P. T., Jr., \& McCrae, R. R. (1992). Revised neo personality inventory (NEO-PI-R) and neo five-factor inventory (NEO-FFI) professional manual. Odessa, FL: Psychological Assessment Resources.

Cropley, M., \& Purvis, L. J. M. (2003). Job strain and rumination about work issues during leisure time: A diary study. European Journal of Work and Organizational Psychology, 12, 195-207.

deCroon, E. M., Sluiter, J. K., \& Blonk, R. W. B. (2004). Stressful work, psychological job strain, and turnover: A 2-year prospective cohort study of truck drivers. Journal of Applied Psychology, 89, 442-454.

De Lange, A. H., Taris, T. W., Kompier, M. A. J., Houtman, I. L. D., \& Bongers, P. M. (2003). "The very best of the millenium": Longitudinal research and the demandcontrol-(support) model. Journal of Occupational Health Psychology, 8, 282-305.

Demerouti, E., Bakker, A. B., \& Bulters, A. J. (2004). The loss spiral of work pressure, work-home interference and exhaustion: Reciprocal relations in a three-way study. Journal of Vocational Behavior, 64, 131-149.

Demerouti, E., Bakker, A. B., Nachreiner, F., \& Schaufeli, W. B. (2001). Job demands-resources model of burnout. Journal of Applied Psychology, 86, 499-512.

Diener, E., Emmons, R. A., \& Larson, R. J. (1985). The satisfaction with life scale. Journal of Personality Assessment, 49, 71-75.

Dormann, C., \& Zapf, D. (2002). Social stressors at work, irritation, and depressive symptoms: Accounting for unmeasured third variables in a multi-wave study. Journal of Occupational and Organizational Psychology, 75, 3358.

Eden, D. (2001). Vacations and other respites: Studying stress on and off the job. In C. L. Cooper \& I. T. Robertson (Eds.), International review of industrial and organizational psychology (pp. 121-146). Chichester: Wiley.

Edwards, J. R., \& Rothbard, N. P. (2000). Mechanisms linking work and family: Clarifying the relationship between work and family constructs. Academy of Management Review, 25, 178-199.

Etzion, D., Eden, D., \& Lapidot, Y. (1998). Relief from job stressors and burnout: Reserve service as a respite. Journal of Applied Psychology, 83, 577-585.

Fredrickson, B. L. (2000). The undoing effect of positive emotions. Motivation and Emotion, 24, 237-258.

Frese, M., Kring, W., Soose, A., \& Zempel, J. (1996). Personal initiative at work: Differences between East and West Germany. Academy of Management Journal, 39, 37-63.

Frese, M., \& Zapf, D. (1994). Action as the core of work psychology: A German approach. In H. C. Triandis, M. D. Dunnette, \& L. M. Hough (Eds.), Handbook of industrial and organizational psychology (2nd ed., Vol. 4, pp. 271-340). Palo Alto, CA: Consulting Psychologists Press.

Fritz, C., \& Sonnentag, S. (2005). Recovery, health, and job performance: Effects of weekend experiences. Journal of Occupational Health Psychology, 10, 187-199.

Fritz, C., \& Sonnentag, S. (2006). Recovery, well-being, and performance-related outcomes: The role of workload and vacation experiences. Journal of Applied Psychology, 91, 936-945.

Fuller, J. A., Stanton, J. M., Fisher, G. G., Spitzmüller, C., Russell, S. S., \& Smith, P. C. (2003). A lengthy look at the daily grind: Time series analyses of events, mood, stress, and satisfaction. Journal of Applied Psychology, 88, 1019-1033.

Garst, H., Frese, M., \& Molenaar, P. C. M. (2000). The temporal factor of change in stressor-strain relationships: A growth curve model on a longitudinal study in East Germany. Journal of Applied Psychology, 85, 417-438.

Geurts, S. A. E., \& Sonnentag, S. (2006). Recovery as an explanatory mechanism in the relation between acute 
stress reactions and chronic health impairment. Scandinavion Journal of Work, Environment and Health, 32, 482-492.

Goldberg, D. (1972). The detection of psychiatric illness by questionnaire. London: Oxford University Press.

Grebner, S., Semmer, N. K., \& Elfering, A. (2005). Working conditions and three types of well-being: A longitudinal study with self-report and rating data. Journal of Occupational Health Psychology, 10, 31-43.

Griffin, J. M., Fuhrer, R., Stansfeld, S. A., \& Marmot, M. (2002). The importance of low control at work and home on depression and anxiety: Do these effects vary by gender and social class? Social Science \& Medicine, 54, 783-798.

Grossman, P., Niemann, L., Schmidt, S., \& Walach, H. (2004). Mindfulness-based stress reduction and health benefits: A meta-analysis. Journal of Psychosomatic Research, 57, 35-43.

Hartig, T., Evans, G. W., Jamner, L. D., Davis, D. S., \& Gärling, T. (2003). Tracking restoration in natural and urban field settings. Journal of Environmental Psychology, 23, 109-123.

Hartig, T., Johansson, G., \& Kylin, C. (2007). The telework tradeoff: Stress mitigation vs. constrained restoration. Applied Psychology: An International Review, 56, 231253.

Heller, D., Watson, D., \& Ilies, R. (2004). The role of person versus situation in life satisfaction: A critical examination. Psychological Bulletin, 130, 574-600.

Hobfoll, S. E. (1998). Stress, culture, and community: The psychology and physiology of stress. New York: Plenum Press.

Jackson, P. R., Wall, T. D., Martin, R., \& Davids, K. (1993). New measures of job control, cognitive demand, and production responsibility. Journal of Applied Psychology, 78, 753-762.

Jacobson, E. (1938). Progressive relaxation. Chicago: University of Chicago Press.

Jex, S. M. (1998). Stress and job performance: Theory, research, and implications for managerial practice. Thousand Oaks, CA: Sage.

John, O. P., \& Srivastava, S. (1999). The big five trait taxonomy: History, measurement, and theoretical perspectives. In L. A. Pervin \& O. P. John (Eds.), Handbook of personality: Theory and research (2nd ed., pp. 102138). New York: Guilford Press.

Kelley, H. H. (1971). Attribution in social interaction. Morristown, NJ: General Learning Press.

Lang, F. R., Lüdtke, O., \& Asendorpf, J. B. (2001). Testgüte und psychometrische Äquivalenz der deutschen Version des Big Five Inventory (BFI) bei jungen, mittelalten und alten Erwachsenen [Validity and psychometric equivalence of the German version of the Big Five Inventory (BFI) in young, middle-aged, and old adults]. Diagnostica, 47, 111-121.

Larson, R. (1989). Is feeling "in control" related to happiness in daily life? Psychological Reports, 64, 775-784.

Lazarus, R. S. (1966). Psychological stress and the coping process. New York: McGraw-Hill.

Lazarus, R. S., \& Folkman, S. (1984). Stress, appraisal, and coping. New York: Springer.

Leitner, K., \& Resch, M. G. (2005). Do the effects of job stressors on health persist over time? A longitudinal study with observational stressor measures. Journal of Occupational Health Psychology, 10, 18-30.

Maslach, C., Schaufeli, W. B., \& Leiter, M. P. (2001). Job burnout. Annual Review of Psychology, 52, 397-422.

Meijman, T. F., \& Mulder, G. (1998). Psychological aspects of workload. In P. J. D. Drenth \& H. Thierry (Eds.), Handbook of work and organizational psychology (Vol. 2: Work psychology, pp. 5-33). Hove, England: Psychology Press.

Meissner, M. (1971). The long arm of the job: A study of work and leisure. Industrial Relations, 10, 239-260.

Mohr, G. (1986). Die Erfassung psychischer Befindensbeeinträchtigungen bei Arbeitern [Assessment of impaired psychological well-being in industrial workers]. Frankfurt/M.: Lang.

Muraven, M., Tice, D. M., \& Baumeister, R. F. (1998). Self-control as limited resource: Regulatory depletion patterns. Journal of Personality and Social Psychology, 74, 774-789.

Parkinson, B., \& Totterdell, P. (1999). Classifying affectregulation strategies. Cognition and Emotion, 13, 277303.

Parkinson, B., Totterdell, P., Briner, R. B., \& Reynolds, S. (1996). Changing moods: The psychology of mood and mood regulation. London: Longman.

Pelletier, C. L. (2004). The effect of music on decreasing arousal due to stress: A meta-analysis. Journal of Music Therapy, 41, 192-214.

Rook, J. W., \& Zijlstra, F. R. H. (2006). The contribution of various types of activities to recovery. European Journal of Work and Organizational Psychology, 15, 218-240.

Rosenfield, S. (1989). The effects of women's employment: Personal control and sex differences in mental health. Journal of Health and Social Behavior, 30, 77-91.

Ruderman, M. N., Ohlott, P. J., Panzer, K., \& King, S. N. (2002). Benefit of multiple roles for managerial women. Academy of Management Journal, 45, 369-386.

Semmer, N. (1984). Streßbezogene Tätigkeitsanalyse [Stress-oriented task-analysis]. Weinheim: Beltz.

Semmer, N. K., Grebner, S., \& Elfering, A. (2004). Beyond self-report: Using observational, physiological, and situation-based measures in research on occupational stress. In P. L. Perrewé \& D. C. Ganster (Eds.), Research in occupational stress and well-being: Emotional and physiological processes and positive intervention strategies (Vol. 3, pp. 205-263). Amsterdam, NL: Elsevier.

Sluiter, J. K., Van der Beek, A. J., \& Frings-Dresen, M. H. W. (1999). The influence of work characteristics on the need for recovery and experienced health: A study on coach drivers. Ergonomics, 42, 573-583.

Sonnentag, S. (2001). Work, recovery activities, and individual well-being: A diary study. Journal of Occupational Health Psychology, 6, 196-210.

Sonnentag, S., \& Bayer, U.-V. (2005). Switching off mentally: Predictors and consequences of psychological detachment from work during off-job time. Journal of Occupational Health Psychology, 10, 393-414.

Sonnentag, S., \& Frese, M. (2003). Stress in organizations. In W. C. Borman, D. R. Ilgen, \& R. J. Klimoski (Eds.), Comprehensive handbook of psychology (Vol. 12: Industrial and organizational psychology, pp. 453-491). Hoboken, NJ: Wiley.

Sonnentag, S., \& Fritz, C. (2006). Endocrinological processes associated with job stress: Catecholamine and 
cortisol responses to acute and chronic stressors. In P. L. Perrewé \& D. C. Ganster (Eds.), Research in organizational stress and well-being: Employee health, coping and methodologies (pp. 1-59). Amsterdam, NL: Elsevier.

Sonnentag, S., \& Jelden, S. (2005). The recovery paradox: Why we don't exercise after stressful days. Poster presented at the conference of the Society for Industrial and Organizational Psychology, Los Angeles.

Sonnentag, S., \& Kruel, U. (2006). Psychological detachment from work during off-job time: The role of job stressors, job involvement, and recovery-related selfefficacy. European Journal of Work and Organizational Psychology, 15, 197-217.

Sonnentag, S., \& Natter, E. (2004). Flight attendants' daily recovery from work: Is there no place like home? International Journal of Stress Management, 11, 366-391.

Stone, A. A., Kennedy-Moore, E., \& Neale, J. M. (1995). Association between daily coping and end-of-day mood. Health Psychology, 14, 341-349.

Strauss-Blasche, G., Ekmekcioglu, C., \& Marktl, W. (2002). Moderating effects of vacation on reactions to work and domestic stress. Leisure Sciences, 24, 237-249.

Strauss-Blasche, G., Reithofer, B., Schobersberger, W., Ekmekcioglu, C., \& Marktl, W. (2005). Effect of vacation on health: Moderating factors of vacation outcome. Journal of Travel Medicine, 12, 94-101.

Taris, T. W., Beckers, D., Verhoeven, L. C., Geurts, S. A. E., Kompier, M. A. J., \& van der Linden, D. (2006). Recovery opportunities, work-home interference, and well-being among managers. European Journal of Work and Organizational Psychology, 15, 139-157.

Taris, T. W., \& Kompier, M. A. J. (2005). Job characteristics and learning behavior. In P. L. Perrewé \& D. C. Ganster (Eds.), Research in occupational stress and wellbeing: Exploring interpersonal dynamics (Vol. 4, pp. 127-166). Amsterdam, NL: JAI Press.

Thayer, R. E., Newman, J. R., \& McClain, T. M. (1994). Self-regulation of mood: Strategies for changing a bad mood, raising energy, and reducing tension. Journal of Personality and Social Psychology, 67, 910-925.

Tinsley, H. E. A., \& Eldredge, B. D. (1995). Psychological benefits of leisure participation: A taxonomy of leisure activities based on their need-gratifying properties. Journal of Counseling Psychology, 42, 123-132.

Totterdell, P., \& Parkinson, B. (1999). Use and effectiveness of self-regulation strategies for improving mood in a group of trainee teachers. Journal of Occupational Health Psychology, 4, 219-232.

van der Klink, J. J. L., Blonk, R. W. B., Schene, A. H., \& van Dijk, F. J. H. (2001). The benefits of interventions for work-related stress. American Journal of Public Health, 91, 270-276.

van Hooff, M. L. M., Geurts, S. A. E., Kompier, M. A. J., \& Taris, T. W. (2007). Workdays, in-between workdays and the weekend: A diary study on effort and recovery. International Archives of Occupational and Environmental Health, 80, 599-613.

van Veldhoven, M., \& Broersen, S. (2003). Measurement quality and validity of the "need for recovery scale." Occupational and Environmental Medicine, 60, i3-i9.

Vohs, K. D., \& Baumeister, R. F. (2004). Unterstanding self-regulation. In R. F. Baumeister \& K. D. Vohs (Eds.), Handbook of self-regulation: Research, theory, and application (pp. 1-9). New York: Guilford Press.

Vollrath, M., \& Torgersen, S. (2000). Personality types and coping. Personality and Individual Differences, 29, 367-378.

Vrijkotte, T. G. M., Van Doornen, L. J. P., \& De Geus, E. J. C. (2000). Effects of work stress on ambulatory blood pressure, heart rate, and heart rate variability. $\mathrm{Hy}$ pertension, 35, 880-886.

Westman, M., \& Eden, D. (1997). Effects of a respite from work on burnout: Vacation relief and fade-out. Journal of Applied Psychology, 82, 516-527.

Zapf, D. (1993). Stress-oriented analysis of computerized office work. European Work and Organizational Psychologist, 3, 85-100.

Zohar, D., Tzischinski, O., \& Epstein, R. (2003). Effects of energy availability on immediate and delayed emotional reactions to work events. Journal of Applied Psychology, $88,1082-1093$.

Received May 22, 2006

Revision received November 17, 2006 Accepted November 20, 2006 